\title{
Opinion
}

\section{Gastroenterology 2021: from the heart of the COVID-19 pandemic}

\author{
Oliver D Tavabie (D) , ${ }^{1}$ Jennie Clough ${ }^{2}$
}

'Institute of Liver Studies, King's College Hospital, London, UK ${ }^{2}$ Gastroenterology, Guy's and Saint Thomas' NHS Foundation Trust, London, UK

\section{Correspondence to} Dr Oliver D Tavabie, King's College Hospital, London SE5 9RS, UK; oliver.tavabie@nhs.net

Received 26 January 2021 Accepted 31 January 2021 Published Online First 5 February 2021

\section{Check for updates}

(c) Author(s) (or their employer(s)) 2021. No commercial re-use. See rights and permissions. Published by BMJ.

To cite: Tavabie OD, Clough J. Frontline Gastroenterology 2021;12:249-251.
Like many across the world, in January we tend to contemplate what we hope to achieve in the upcoming year. Of course, these are not hard and fast objectives due to a combination of overambition (which frequently leads to my gym goals being modified) and unforeseen circumstance. It would be an understatement to say that 2020 was affected by unforeseen circumstance. Nevertheless, as healthcare professionals we have united in our response to the COVID-19 pandemic and in our attempts to continue to provide a quality service for our patients. Here, we look back over the past year and review what we have learnt about COVID-19 and its effects on how we work as gastroenterologists as well as what questions remain unanswered.

The pandemic was initially accompanied with an explosion of case reports. Flicking through Twitter on the commute, one learnt that 'COVID-19 causes pancreatitis $^{1}$,' 'COVID-19 causes encephalitis ${ }^{2}$, and 'COVID-19 causes orchitis ${ }^{3}$ ' which left you wondering what inflammatory condition the disease was not associated with. It soon became apparent that gastrointestinal symptoms were not uncommon and that they may be associated with a more severe disease phenotype. ${ }^{45}$ Abnormal liver function tests are frequently observed and may be associated with a more severe disease phenotype. ${ }^{67}$ Whether or not this represents a direct effect of SARS-CoV-2 infection is still up for debate and long-term follow-up data are required to further understand the implications of developing COVID-19 on the function of the gastrointestinal tract.

The virulence and transmissibility of SARS-CoV-2 necessitated rapid changes in how we had to work. There were clear concerns regarding the risks of endoscopy to both patients and staff ${ }^{8}$ given the potential for aerosolisation and faecal transmission of the virus, ${ }^{9}$ although subsequent reports demonstrated that the use of appropriate PPE significantly ameliorates this risk. ${ }^{10}$ Predicting the risk of SARS-CoV-2 infection to our patients has been challenging and the British Society of Gastroenterology (BSG) worked quickly to develop guidance regarding which patient groups should shield. ${ }^{11} 12$ International registry work provided observations demonstrating increased risk of adverse outcome in patients with decompensated liver disease ${ }^{13}$ and inflammatory bowel disease (IBD) using corticosteroids, but not those using anti-TNF agents ${ }^{14}$ or patients post liver transplant. ${ }^{15}$ However, further work is required to reassure both patients and healthcare professionals managing patients with chronic gastrointestinal disorders regarding the risk of SARS-CoV-2 infection such that appropriate treatment and lifestyle advice can be offered.

In order to protect our patients and respond to the surge of patients with COVID-19, our healthcare service evolved into a 'COVID-centric' machine. With the workforce redeployed to facilitate this, great sections of gastroenterology services, including IBD services, either stopped or were significantly reduced. ${ }^{16}$ To stop the spread of the virus, many patients stayed at home. Secondary effects attributed to a reduction of service provision and the avoidance of healthcare have been sadly observed, including increased mortality from upper gastrointestinal bleeding in London ${ }^{17}$ and a reduction in endoscopic gastrointestinal cancer diagnoses at a large UK centre. ${ }^{18}$ Furthermore, nationwide lockdowns have led to both an increase in sedentary behaviour and alcohol consumption ${ }^{19}$ with a subsequent increase in the number of patients with severe alcohol-related liver disease observed in a London teaching hospital 
following relaxation of the lockdown. ${ }^{20}$ This is likely to be the tip of the iceberg with more secondary effects becoming apparent as time passes.

As Benjamin Franklin said 'out of adversity comes opportunity'. The pandemic has led to great innovation and re-evaluation of how we work as gastroenterologists, with many units demonstrating great flexibility in adapting their services. We have realised that we need to make patient pathways simpler and with a greater focus on non-invasive testing. Examples of this are a 'no biopsy approach' to the management to coeliac disease, ${ }^{21}$ clear guidance management strategies and when to refer patients with potential upper gastrointestinal physiology disorders ${ }^{22}$ and telemedicine which has been used to great effect across the breadth of gastroenterology. ${ }^{23-25}$ Although many of us miss seeing our patients face-to-face, there are undoubtedly benefits for patients in terms of the convenience of avoiding travel to hospitals with secondary positive effects on the environment.

When we must see patients, we should aim to streamline this experience to prevent multiple attendances, such as the 'one-stop' approach to assessing patients with liver disease adopted in Queensland, Australia. ${ }^{26}$ Moreover, we have realised the importance of effectively communicating changes to service provision to patients, particularly given the volume of misinformation available on social media. A team from Birmingham demonstrated that patients with IBD were less likely to be concerned about their risk of contracting COVID-19 if they had a single interaction with the IBD service (which included a generic letter or visit to the Crohn's and Colitis UK website). ${ }^{27}$ Ongoing work with patients is required to continue to simplify and innovate care provision to ensure the same high standards are maintained while reducing the risk of SARS-CoV-2 exposure.

Despite the lessons of 2020, the new year has brought fresh challenges. We are now in the midst of a greater surge of cases and mortality than during the peak of the first wave. On the horizon, the vaccination programme provides hope. While the BSG has issued guidance recommending vaccination of patients with IBD and liver disease, ${ }^{28} 29$ we need to rapidly assimilate data regarding a vaccination strategy across the breadth of patients with gastroenterology conditions. The pandemic has brought us together as healthcare professionals globally as we share responsibility in providing care for patients, as well as through a collaborative research effort to respond to the direct and indirect effects of COVID-19. We hope that this united approach to healthcare continues and at Frontline Gastroenterology, we remain dedicated to promoting work that guides and improves practice at the coalface for healthcare professionals and patients. Now to make a list of aims for $2021 \ldots$

Twitter Jennie Clough@jennie_clough
Contributors ODT drafted initial manuscript and JC made critical revision of manuscript. Both authors approved the final version of the manuscript.

Funding The authors have not declared a specific grant for this research from any funding agency in the public, commercial or not-for-profit sectors.

Competing interests ODT has received consultancy fees from Gilead Sciences. Both authors are Trainee Associate Editors at Frontline Gastroenterology.

Patient consent for publication Not required.

Provenance and peer review Not commissioned; externally peer reviewed.

This article is made freely available for use in accordance with BMJ's website terms and conditions for the duration of the covid-19 pandemic or until otherwise determined by BMJ. You may use, download and print the article for any lawful, noncommercial purpose (including text and data mining) provided that all copyright notices and trade marks are retained.

\section{ORCID iD}

Oliver D Tavabie http://orcid.org/0000-0003-4693-6632

\section{REFERENCES}

1 Aloysius MM, Thatti A, Gupta A, et al. COVID-19 presenting as acute pancreatitis. Pancreatology 2020;20:1026-7.

2 Efe IE, Aydin OU, Alabulut A, et al. COVID-19-Associated encephalitis mimicking glial tumor. World Neurosurg 2020;140:46-8.

3 Bridwell RE, Merrill DR, Griffith SA, et al. A coronavirus disease 2019 (COVID-19) patient with bilateral orchitis: a case report. Am J Emerg Med 2020;16.

4 Beattie RM, Ashton JJ, Penman ID. COVID-19 and the gastrointestinal tract: emerging clinical data. Frontline Gastroenterol 2020;11:290-2.

5 Beattie RM, Ashton JJ, Penman ID. COVID-19 and the gastrointestinal tract: recent data. Frontline Gastroenterol 2020;11:371-4.

6 Lok J, Gess M. Liver dysfunction in COVID-19: a useful prognostic marker of severe disease? Frontline Gastroenterol 2020;2012:flgastro-2020-101689.

7 Yeoman A, Maggs DR, Gardezi SAA. Incidence, pattern and severity of abnormal liver blood tests among hospitalised patients with SARS-COV2 (COVID-19) in South Wales. Frontline Gastroenterol 2020;5:flgastro-2020-101532.

8 Edwards C, Penman ID, Coleman M. Gastrointestinal endoscopy during COVID-19: when less is more. Frontline Gastroenterol 2020;11:256-7.

9 Xiao F, Sun J, Xu Y, et al. Infectious SARS-CoV-2 in feces of patient with severe COVID-19. Emerg Infect Dis 2020;26:1920-2.

10 Repici A, Aragona G, Cengia G, et al. Low risk of COVID-19 transmission in Gi endoscopy. Gut 2020;69:1925-7.

11 BSG. BSG expanded consensus advice for the management of IBD during the COVID-19 pandemic. British Society of gastroenterology, 2020. Available: https://www.bsg.org.uk/ covid-19-advice/bsg-advice-for-management-of-inflammatorybowel-diseases-during-the-covid-19-pandemic/ [Accessed 22 Jan 2021].

12 BSG. Defining patient groups that should be considered for Shielding/Highly vulnerable categories. British Society of Gastroenterology 2020.

13 Marjot T, Moon AM, Cook JA, et al. Outcomes following SARS-CoV-2 infection in patients with chronic liver disease: an international registry study. J Hepatol 2020. doi:10.1016/j. jhep.2020.09.024. [Epub ahead of print: 06 Oct 2020].

14 Brenner EJ, Ungaro RC, Gearry RB, et al. Corticosteroids, but not TNF antagonists, are associated with adverse COVID-19 outcomes in patients with inflammatory bowel diseases: 
results from an international registry. Gastroenterology 2020;159:481-91.

15 Webb GJ, Marjot T, Cook JA, et al. Outcomes following SARS $\mathrm{CoV}-2$ infection in liver transplant recipients: an international registry study. Lancet Gastroenterol Hepatol 2020;5:1008-16.

16 Kennedy NA, Hansen R, Younge L, et al. Organisational changes and challenges for inflammatory bowel disease services in the UK during the COVID-19 pandemic. Frontline Gastroenterol 2020;11:343-50.

17 Tavabie OD, Clough JN, Blackwell J. Reduced survival after upper gastrointestinal bleed endoscopy in the COVID-19 era is a secondary effect of the response to the global pandemic: a retrospective cohort study. Frontline Gastroenterol 2020;52:flgastro-2020-101592.

18 Longcroft-Wheaton G, Tolfree N, Gangi A, et al. Data from a large Western centre exploring the impact of COVID-19 pandemic on endoscopy services and cancer diagnosis. Frontline Gastroenterol 2020;42:flgastro-2020-101543.

19 ONS. Retail sales. office for national statistics statistical Bulletin, 2020. Available: https://www.ons.gov.uk/business industryandtrade/retailindustry/bulletins/retailsales/march2020 [Accessed 21 Jan 2020].

20 Cargill Z, Kattiparambil S, Hansi N, et al. Severe alcoholrelated liver disease admissions post-COVID-19 lockdown: Canary in the coal mine? Frontline Gastroenterol 2020:flgastro-2020-101693.

21 Penny HA, Raju SA, Lau MS. Accuracy of a no-biopsy approach for the diagnosis of coeliac disease across different adult cohorts. Gut 2020;18:gutjnl-2020-320913.

22 Sykes C, Parker H, Jackson W, et al. Triage guidance for upper gastrointestinal physiology investigations during restoration of services during the COVID-19 pandemic. Frontline Gastroenterol 2020;18:flgastro-2020-101632.
23 Muhammad H, Reeves S, Ishaq S, et al. Telephone clinic improves gluten-free dietary adherence in adults with coeliac disease: sustained at 6 months. Frontline Gastroenterol 2020;155:flgastro-2020-101643.

24 Serper M, Cubell AW, Deleener ME, et al. Telemedicine in liver disease and beyond: can the COVID-19crisis lead to action? Hepatology 2020;72:723-8.

25 Tang J, Huang Z, Guo H, et al. Online video clinic Satisfies the medical requirements of patients with IBD during the COVID-19 outbreak. Am J Gastroenterol 2020. doi:10.14309/ajg.0000000000001033. [Epub ahead of print: 29 Oct 2020].

26 Eqbal A, Wickremeratne T, Turner S. One-Stop shop for variceal surveillance: integration of unsedated ultrathin endoscopy into the routine clinic visit. Frontline Gastroenterol 2021;38:flgastro-2020-101680.

27 Mir N, Cheesbrough J, Troth T, et al. COVID-19-related health anxieties and impact of specific interventions in patients with inflammatory bowel disease in the UK. Frontline Gastroenterol 2020;17:flgastro-2020-101633.

28 BSG. British Society of gastroenterology inflammatory bowel disease section and IBD clinical research Group position statement on SARS-CoV2 vaccination. British Society of Gastroenterology 2020 https://www.bsg.org.uk/covid-19advice/british-society-of-gastroenterology-inflammatory-boweldisease-section-and-ibd-clinical-research-group-positionstatement-on-sars-cov2-vaccination/

29 BSG. A joint statement on vaccination for Sars-CoV2 in patients with liver disease. British Society of gastroenterology 2020 https://www.bsg.org.uk/covid-19-advice/a-jointstatement-on-vaccination-for-sars-cov2-in-patients-with-liverdisease/ 